\title{
The effect of exercise training on pulmonary function in persons with quadriplegia
}

\author{
L Crane MMSc PT CCS,${ }^{1} \mathrm{~K}$ Klerk BS PT, ${ }^{3}$ A Ruhl MSPT PT,${ }^{4} \mathrm{P}$ Warner MSPT PT, ${ }^{5}$ \\ C Ruhl BS PT, ${ }^{4} \mathrm{~K}$ E Roach PhD PT ${ }^{2}$
}

${ }^{1}$ Instructor, ${ }^{2}$ Assistant Professor, Division of Physical Therapy, University of Miami, Coral Gables, Florida 33146; ${ }^{3}$ Supervisor, Spinal Cord Unit, Department of Physical Therapy, Jackson Memorial Hospital, Miami, Florida; ${ }^{4}$ Staff Physical Therapist, Miami Physical Therapy Associates Inc, Miami, Florida; ${ }^{5}$ Staff Physical Therapist, Central Arizona Medical Centre, Florence, Arizona, USA.

\begin{abstract}
The purpose of this study is to determine if measures of pulmonary function are different between endurance trained and nontrained groups of persons with quadriplegia. After minimum criteria were met, 57 subjects with spinal cord injuries ranging from $\mathrm{C} 5-\mathrm{T} 1$ were surveyed to determine type, duration and intensity of exercise training for the previous 6 months. Subjects were assigned to the trained or untrained groups based on the operational definitions of 'trained' $v s$ 'untrained'. A computerized spirometer was used to test forced vital capacity (FVC), forced mid-expiratory flow $\left(\mathrm{FEF}_{25-75 \%}\right)$ and maximum voluntary ventilation (MVV) as indicators of respiratory muscle strength, airway patency and repiratory muscle endurance, respectively. Independent $t$ tests and Wilcoxon-Mann-Whitney nonparametric tests revealed no significant differences between the 'trained' and 'untrained' groups for the pulmonary functions. Correlation analysis revealed a moderate relationship $(r=0.498 ; p \leqslant 0.0001)$ between a derived continuous variable called the weighted training equivalent (WTE) and FVC. Regression analysis revealed that WTE and level of injury accounted for approximately $30 \%$ of the variance of FVC with WTE contributing $25 \%$. Exercise training may positively affect FVC in persons with quadriplegia.
\end{abstract}

Keywords: quadriplegia; tetraplegia; pulmonary function testing; exercise training; spinal cord athlete.

\section{Introduction}

Approximately $67.9 \%$ of all spinal cord injured (SCI) persons have frequent respiratory problems such as pneumonia, atelectasis and respiratory infections due to the decrease in active respiratory musculature. ${ }^{1,2}$ The degree to which the respiratory muscles are impaired depends on the level of the lesion. ${ }^{3,4}$ Lesions in the lower thoracic region of the spinal cord will reduce function in the abdominal musculature which causes a decrease in forced expiration. Lesions in the upper thoracic level will additionally reduce function in the intercostal muscles, thereby reducing inspiration. Higher levels of injury may impair various accessory muscles of ventilation. ${ }^{5}$
Spinal cord injury can impair ventilation in a number of ways. Absent or decreased function of the diaphragm, abdominal and intercostal muscle function results in decreased inspiratory and expiratory volumes. $^{3,6-12}$ Decreased function of respiratory musculature also results in decreased rib cage compliance and motion. ${ }^{13-15}$ Flaccid abdominal musculature and subsequent low intraabdominal pressures result in a decreased diaphragm efficiency and reduced pulmonary function. . $^{15-17}$

The reduced function of respiratory musculature secondary to SCI results in a decrease in pulmonary function. Forced vital capacity (FVC), forced expiratory 
volume $(\mathrm{FEV})$, minute ventilation $\left(\mathrm{V}_{\mathrm{E}}\right)$ and tidal volume $\left(\mathrm{V}_{\mathrm{T}}\right)$ are all decreased. ${ }^{3.5}$ The reduction of FVC has been shown to be an important risk factor for respiratory complications such as pneumonia and atelectasis. Reines \& Harris ${ }^{18}$ studied pulmonary function and incidence of respiratory infection of individuals with SCI ranging from $\mathrm{C} 1-\mathrm{L} 5$ (greater than $50 \%$ of the subjects had injuries between the $\mathrm{C} 5-\mathrm{C} 7$ level). The mean FVC for the subjects not developing complications was $1865 \pm 850 \mathrm{cc}$ as compared to those developing complications who averaged $1127 \pm 410 \mathrm{cc}$. Therefore, they concluded that FVC was an important predictor of respiratory difficulties.

Although pulmonary function is impaired after SCI, individuals with quadriplegia have been shown to improve flow rates and volumes with exercise. Inspiratory muscle training in the acute stage of quadriplegia resulted in increases in VC, inspiratory and expiratory volumes. ${ }^{19}$ Phillips, et al $^{20}$ found a significant increase in forced vital capacity (FVC) and forced expiratory volume $\left(F E V_{1}\right)$ as a result of an 8 week functional electrical stimulation (FES) bike ergometry training program.

In a study by Walker et al, ${ }^{4} 15$ subjects with quadriplegia at least 2 years post injury, participated in a 7-12 week training program of incentive spirometry and arm ergometry. The results indicated that arm ergometry in conjunction with incentive spirometry significantly increased FVC by $23.6 \%$.

One study has examined the effects of aerobic training on pulmonary function in the paraplegic population (L D Crane et al, unpublished). Twenty-two endurance trained paraplegic athletes ranging in age from 22 to 47 and 23 paraplegic nonathletes ranging in age from 19 to 51 volunteered for this study. The median level of injury was T6-7 for the athletes and T10 for the nonathletes. Results indicated that the athletes had a statistically significant higher FVC and maximum voluntary ventilation (MVV) as compared to the nonathletes.

Respiratory complications are a major cause of morbidity and mortality in the quadriplegic population.,.$^{3,6}$ If aerobic training increases pulmonary function in subjects with quadriplegia, then the incidence of problems such as atelectasis and pneumonia may be reduced. The purpose of this study is to determine if measures of pulmonary function are different for endurance trained and for nontrained groups of quadriplegic SCI persons.

\section{Methods}

\section{Design of study}

In designing this study, two assumptions were made regarding the factors which contribute to training. These assumptions were (1) continuous exercise for a specific duration and time is required and (2) energy expenditure contributes to training. ${ }^{21}$ The first assumption was made to assist with determining which subjects should be classified as trained or untrained. The second assumption made it possible to weight the various activities of the subjects in order to examine the effects of activity on pulmonary function.

Since classifying persons with quadriplegia as trained or untrained is difficult, this study addressed the question of whether exercise training has an effect on pulmonary function in two ways. First a quasi-experimental, cross-sectional design was utilized to compare pulmonary function between a group of subjects who met the operational definition of 'trained' and a group of subjects who did not meet the criteria. The second method employed a correlational design and regression analysis to determine the association between level of training and pulmonary function.

Pulmonary function was evaluated in terms of forced vital capacity (FVC), forced midexpiratory flow $\left(\mathrm{FEF}_{25-75 \%}\right)$ and maximal voluntary ventilation (MVV). Forced vital capacity and MVV were selected in order to test for strength and endurance of respiratory musculature while $\mathrm{FEF}_{25-75 \%}$ measured airway patency and screened for presence of obstructive lung disease. ${ }^{22}$

Level of training was calculated from the exercise training components reported on the questionaire. Training equivalent (TE), a composite variable, was the product of duration (minutes) of each training session (in the case of quad rugby training duration 
was reduced by $25 \%$ of the time reported due to the intermittent nature of this activity); frequency (days/week); and number of consecutive weeks of training immediately prior to testing. The sum of the products for each sport in which a subject participated comprised the variable unweighted training equivalent (UTE).

The variable UTE indicated the amount of time a subject trained during the preceding 6 months, but it did not account for the energy expenditure of that training. A weighting system was developed to reflect both the duration and the type of exercise training. Table I presents the weighting system used to create the weighted training equivalent (WTE) variable.

\section{Subjects}

Fifty-seven subjects participated in this study. Subjects were eligible for inclusion in this study if they met the following minimum criteria: (1) spinal cord injury between the levels of C5-T1, (2) at least 2 years post injury and (3) Frankel scale classification groups $\mathrm{A}, \mathrm{B}$, or $\mathrm{C}$. The Frankel scale specified the degree of completeness of the injury and helped ensure that all subjects did not have functional voluntary motor ability below the level of the lesion. Subjects were excluded from the study if they had an infectious disease, acute respiratory disease or history of chronic pulmonary disease.

Subjects were classified as trained if they met the following additional criteria: participation in any one or a combination of swimming; wheelchair road racing; quad rugby; kayaking; wheelchair basketball; arm ergometry at least three times per week, 30 minutes each session for a minimum of 6 months prior to testing. These criteria were partially based on the first assumption that a specific duration of con-

Table I Weighting system for computation of weighted training equivalent (WTE)

I Each major type of continuous exercise was assigned a weighting (fraction) based on its correlated relative energy expenditure:

A First, correlated (or paralled) able bodied sports activities were identified (this was done because no relative energy expenditure data are available for the exercise types represented in this study)

B Energy expenditure $(\mathrm{kcal} / \mathrm{min})$ for the correlated activities were determined from a published table. ${ }^{23}$ When ranges of values were given for different velocities, the average was used

$\mathrm{C}$ The activity with highest energy expenditure was assigned a value of 1 and the remaining activities' weights were calculated

\begin{tabular}{|c|c|c|c|}
\hline $\begin{array}{l}\text { Quad sport } \\
\text { activity }\end{array}$ & $\begin{array}{l}\text { Able bodied } \\
\text { correlated activity }\end{array}$ & $\begin{array}{c}\text { Energy } \\
\text { expenditure (23) } \\
(\mathrm{kcal} / \mathrm{min} / \mathrm{kg})\end{array}$ & Weight used \\
\hline $\begin{array}{l}\text { Wheelchair road-racing } \\
\text { Swimming }\end{array}$ & $\begin{array}{c}\text { Running (approx } 8 \mathrm{~min} / \mathrm{mile} \text { ) } \\
\text { Swimming }\end{array}$ & $\begin{array}{l}0.210 \\
0.160\end{array}$ & $\begin{array}{l}1 \\
0.75\end{array}$ \\
\hline $\begin{array}{l}\text { Upper extremity } \\
\text { ergometry } \\
\text { (intermittent) } \\
\text { Quad rugby } \\
\text { Wheelchair } \\
\text { basketball }\end{array}$ & Cycling & 0.135 & 0.65 \\
\hline Kayaking & Canoeing & 0.080 & 0.40 \\
\hline
\end{tabular}

II The training equivalent values for each sport activity was multiplied by its respective weighting

III The WTE values were then added for those subjects who trained in more than one activity

IV The resulting value was then analyzed as WTE for that subject 
tinuous exercise is required for training effects to occur. Individuals who had trained less time per week or who had trained for fewer than 6 months, were classified as untrained along with subjects who had not trained at all. Therefore, the threshold between trained and untrained was somewhat arbitrary. ${ }^{24}$

Table II presents the characteristics of both the trained and 'untrained' groups including age, years post injury and injury level. There was no significant difference between the groups for age or years post injury. The median level of injury for the trained group was C6 and C5-6 for the untrained group.

\section{Instrumentation}

The instrument used to measure pulmonary function was the Vitalograph-Compact spirometer (Vitalograph Inc, 8347 Quivira Road, Linexa, Kansas 66215, USA). This is a portable computerized spirometer which measures inspired and expired air through a flowhead. Volume calibration within $\pm 3 \%$ was done before each test session. The parameters measured were forced vital capacity (FVC) in liters, forced midexpiratory flow $\left(\mathrm{FEF}_{25-75 \%}\right)$ in liters/second and maximal voluntary ventilation (MVV) in liters/minute. Interrater reliability for measurement of FVC, $\mathrm{FEF}_{25-75 \%}$ and $\mathrm{MVV}$ in spinal cord injured adults was established by the two testers prior to this study ( $r=0.9018, r=0.7923$ and $r=0.9258$ respectively).

\section{Procedure}

Each subject signed an informed consent prior to testing. A questionnaire was used to ensure that all subjects met the minimum criteria for participation in this study and to determine the trained or untrained status according to the subjects' self reports.

All subjects were tested identically. All remained seated in their wheelchairs with a belt at the axillary level to prevent trunk flexion. Abdominal binders were not worn by any subjects. In the event that a subject was unable to hold the flowhead, the tester assisted by holding it.

Subjects were instructed on the performance of the FVC test and the tester demonstrated the maneuver. While wearing a noseclip, the subject maximally inhaled; then through the flowhead, the subject maximally exhaled and inhaled one time producing a flow-volume loop. This was recorded by the Vitalograph-Compact. The test was performed a maximum of three times with 1-2 minutes' rest between each test. If the difference in FVC was less than $5 \%$ between the first and second trials, the subject was not required to repeat the test a third time. During the FVC test $\mathrm{FEF}_{25-75 \%}$ was also measured and did not require an additional test procedure. The best test results were computed and printed by the Vitalograph-Compact.

During a 2 minute rest period, the subject was instructed on the performance of the MVV test and the tester demonstrated the maneuver. The subject then performed the MVV test by breathing as deeply and quickly as possible through the flowhead for 12 seconds. Standardized verbal encouragement was given to each subject by the tester. The Vitalograph-Compact computed and printed the results.

The Vitalograph-Compact reported predicted, actual and percent-predicted values

Table II Characteristics of the trained and untrained groups

\begin{tabular}{lcc} 
& Trained $(n=27)$ & Untrained $(n=30)$ \\
\hline Age $^{\mathrm{a}}$ (years) & $30.07 \pm 6.23$ & $31.60 \pm 6.81$ \\
Years post injury $^{\mathrm{a}}$ & $8.82 \pm 4.96$ & $10.55 \pm 6.74$ \\
Injury level $^{\mathrm{b}}$ & $\mathrm{C} 6$ & $\mathrm{C} 5-6$ \\
Males & 26 & 27 \\
Females & 1 & 3
\end{tabular}

${ }^{a}$ mean \pm standard deviation.

${ }^{\mathrm{b}}$ median level. 
for each subject. The percent-predicted values, based upon normative values for healthy individuals (corrected for age, gender, height and race), were used for comparison of the data.

\section{Data analysis}

An independent $t$ test was used to compare trained and untrained subjects for FVC, $\mathrm{FEF}_{25-75 \%}, \mathrm{MVV}$, age and years post injury using the Statview SE program (Statview SE + Graphics, Abacus Concepts, Inc, 1984 Bonita Ave, Berkeley, CA, 94704, USA, 1988). The baseline characteristics of the trained and untrained groups were compared using Student's $t$ test and $\chi^{2}$ test for independent groups.

The Wilcoxon-Mann-Whitney (WMW) test was employed to analyze the data in addition to the $t$ test reported above. This additional analysis was done because the scale of measurement (percentiles) of the pulmonary function data is not interval level, but ordinal level. This violates one assumption of the parametric $t$ test. The WMW test is used to test whether two independent groups have been drawn from the same population and is one of the most powerful of the nonparametric tests. ${ }^{25}$

Using SAS Version 6 (SAS Institute Inc, Cary, North Carolina, USA, 1989), the association between training level and pulmonary function was explored by calculating a Pearson product moment correlation. To explore the degree to which training level predicted pulmonary function, a linear regression was performed both with and without level of SCI in the model.

\section{Results}

Independent, one-tailed $t$ tests revealed no significant difference between the trained and untrained groups for the dependent variables $\mathrm{FVC}, \mathrm{FEF}_{25-75 \%}$ or $\mathrm{MVV}$ at $p \leqslant 0.05$ (Table III). The WMW analyses also revealed no significant differences ( $p$ values $0.056,0.446$ and 0.142 for $\mathrm{FVC}$, FEF an MVV respectively). A power analysis was performed for the trained and untrained groups for FVC and the power was 0.86 (equivalent to $1-\beta$ and indicates the probability of choosing the alternate hypothesis if it were true).

Correlation of the three pulmonary dependent variables and weighted training equivalent (WTE) revealed a moderate correlation ( $r=0.498)$ between FVC and WTE which was significant at $p \leqslant 0.0001 .^{26}$ A regression analysis model was created to examine the effects of the unweighted training equivalent (UTE), WTE and WTE plus level of injury upon FVC. As UTE, WTE and WTE plus level of injury were added to the model, the coefficient of determination $\left(R^{2}\right)$ increased as follows: $R^{2}=0.2039$, 0.2481 and 0.2962 respectively, with $p \leqslant 0.0001$ (see Table IV).

\section{Discussion}

Persons with quadriplegia have frequent respiratory problems such as atelectasis and pneumonia due to a decrease in pulmonary function and active respiratory musculature. This project was designed to compare the pulmonary function of endurance trained

Table IV Summary statistics from regression model analysis $(n=54)$

\begin{tabular}{lcc}
\hline 'Model' & $R^{2}$ & $p$ value \\
\hline UTE & 0.2039 & 0.0006 \\
WTE & 0.2481 & 0.0001 \\
WTE + level of injury & 0.2962 & 0.0001 \\
\hline
\end{tabular}

Table III Means, standard deviations and $t$ test $p$ values of percent predicted values for trained and untrained groups

\begin{tabular}{lccc}
\hline & Trained $(n=27)$ & Untrained $(n=30)$ & $p$ values $(t$ test $)$ \\
\hline FVC & $66.59 \pm 16.18$ & $60.25 \pm 15.14$ & 0.056 \\
FEF25-75\% & $61.59 \pm 25.10$ & $63.23 \pm 24.76$ & 0.4025 \\
MVV & $66.74 \pm 16.67$ & $61.60 \pm 15.75$ & 0.1113 \\
\hline
\end{tabular}


and untrained subjects with quadriplegia. The results of this study suggest no significant difference between the trained and untrained subjects with quadriplegia as we operationally defined 'trained'. However, forced vital capacity was significantly correlated with the level of exercise training reported by the subjects.

The lack of statistically significant differences between the trained and untrained subjects for FVC and MVV is most likely due to the methodological problem of defining 'trained' for persons with quadriplegia. An able bodied person can generally receive the training effects with 30 minutes of aerobic activity, 3-5 times per week at $70 \%$ of maximum heart rate. ${ }^{22}$ A study done by Crane et al (unpublished) found a significant difference between trained and untrained persons with paraplegia for FVC and MVV. They defined a trained person with paraplegia as one who participated in aerobic activity three times per week for 30 minutes for at least 6 months consecutively. For persons with quadriplegia, there is no standard definition for 'trained'. Using the same definition of 'trained' for persons with paraplegia and quadriplegia may not be appropriate due to the differences in available musculature and responses to exercise.

Additionally, the criteria for trained versus untrained was dichotomous and there was no consideration for those individuals who participated in some exercise, but less than the operational definition. Since we do not know how much exercise is required for training effects in persons with quadriplegia, those persons who exercise less than the operational definition may have been trained, but were classified as untrained or vice versa.

Another problem with determining the effects of training on persons with quadriplegia is related to the disruption of their autonomic nervous system. This disruption limits the heart rate and blood pressure changes that normally occur during exercise and makes it difficult to determine the intensity of the exercise performed and the effects that training has on the body. Therefore creating an operational definition of 'trained' for persons with quadriplegia (especially in a cross-sectional study) is complicated.

Unweighted training equivalent (UTE) and WTE were created in order to examine the relationship between a continuous variable of level of training and pulmonary function. These variables represented the duration, frequency and energy requirements of training during the 6 months prior to testing and were necessary to study the effects of any level of activity upon pulmonary function. The weighting of the variables provided a more standardized way to compare the exercise programs of the subjects since their exercise regimes comprised many different activities.

The results showed a moderate positive correlation between WTE and FVC which was statistically significant. This suggests that as the training equivalent value increases, so does FVC. The regression model proposes that exercise, in addition to the level of injury, can have an effect on FVC. Together, level of injury and amount of exercise may explain approximately $30 \%$ of the variance related to FVC with exercise contributing approximately $25 \%$ and level of injury $5 \%$. Even without employing the weighting system, the continuous variable UTE still accounted for a significant percent of variability in FVC (20.4\%).

A possible explanation for the small increase in $R^{2}$ when level of injury was added to the regression model may be that the injury levels of the subjects ranged from $\mathrm{C} 5-\mathrm{T} 1$. With this range in level of injury, there is little change in available respiratory musculature; therefore level of injury had less of an impact on FVC as compared to the amount of exercise in this population.

Clinically these results are significant because if FVC can be improved with exercise, then exercise may reduce the incidence of pulmonary problems, such as atelectasis and pneumonia, in the quadriplegic population. Based on the results of this study, further research into this and related questions is justified. More studies are needed to examine the effects of aerobic exercise on pulmonary function. In addition, a prospective study would reduce the potential errors inherent in self reporting of activity level as well as control the frequency, intensity and duration of exercise. 


\section{Conclusion}

The results of this study support the hypothesis that there is a positive correlation between endurance training and FVC in persons with quadriplegia. In addition, a continuous variable like WTE may be a good predictor for changes in FVC in this population. Continued study of this and related areas may lead to improvement in the overall treatment of persons with quadriplegia.

\section{References}

1 Carter RE (1987) Respiratory aspects of spinal cord injury management. Paraplegia 25: 262-266.

2 Clough P (1989) Respiratory causes. In: Scully RM, Barnes MR, editors. Physical Therapy. Philadelphia: JB Lippincott Company, Philadelphia: 280-281.

3 Ohry A, Molho M, Rozin R (1975) Alterations of pulmonary function in spinal cord injured patients. Paraplegia 13: 101-108.

4 Walker J, Cooney M, Norton S (1989) Improved pulmonary function in chronic quadriplegia after pulmonary therapy and arm ergometry. Paraplegia 27: 278-283.

5 Mackenzie CF, Imle PC, Ciesla N (1989) Chest Physiotherapy in the Intensive Care Unit. 2nd edn. Williams \& Wilkins, Baltimore.

6 Goldman JM, Silver JR, Lehr RP (1986) An electromyographic study of the abdominal muscles of tetraplegic patients. Paraplegia 24: 241-246.

7 Ledsome JR, Sharp JM (1981) Pulmonary function in acute cervical cord injury Am Rev Respir Dis 124: 41-44.

8 Eriksson P, Lofstrom L, Ekblom B (1989) Aerobic power during maximal exercise in untrained and well-trained persons with quadriplegia and paraplegia. Scand J Rehabil Med 20: 141-1.57.

9 Silver JR, Lehr RP (1981) Electromyographic investigation of the diaphram and intercostal muscles in tetraplegics. J Neurol Neurosurg Psychiatry 44: 837-842.

10 Goldman JM, Williams SJ, Denison DM (1988) The rib cage and abdominal components of respiratory system compliance in tetraplegic patients. Eur Respir J 1: 242-247.

11 Loveridge BM, Dubo HI (1990) Breathing pattern in chronic quadriplegia. Arch Phys Med Rehabil 71: 495-499.

12 Guttmann L, Silver JR (1965) Electromyographic studies on reflex activity of the intercostal and abdominal muscles in cervical cord lesions. Paraplegia 3: 1-22.

13 Estenne M, Keilporn A, Delhez L et al (1993) Chest wall stiffness in patients with chronic respiratory muscle weakness. Am Rev Respir Dis 128: 1002-1007.

14 Berczeller PH, Bezkor MF (1986) Medical Complications of Quadriplegia. Chicago: Year Book Medical Publishers Inc, Chicago: 25-29.

15 Mortola JP, Sant'Ambrogio G (1978) Motion of the rib cage and the abdomen in tetraplegic patients. Clin Sci Mol Med 54: 25-32.

16 DeTroyer A, Estenne M, Vincken W (1986) Rib cage motion and muscle use in high tetraplegics. Am Rev Respir Dis 133: 1115-1119.

17 Scanlon PD, Loring SH, Pichurko BM et al (1989) Respiratory mechanics in acute quadriplegia. Am Rev Respir Dis 139: 615-620.

18 Reines HD, Harris RC (1987) Pulmonary complications of acute spinal cord injuries. Neurosurgery 21: $193-196$.

19 Ciesla N, Simpson N, Derrickson J, Salmon M (1989) A comparison of two different breathing exercises for quadriplegic patients (abstract). Phys Ther 69: 393.

20 Phillips CA, Danopulos D, Kezdi P, Hendershot, D (1989) Muscular, respiratory and cardiovascular responses of quadriplegic persons to an FES bicycle ergometer conditioning program. Int J Rehabil Res 12: $147-157$.

21 McArdle WD, Katch FI, Katch VL (1986) Exercise Physiology: Energy, Nutrition, and Human Performance. 2nd edn. Lea and Febiger, Philadelphia.

22 Irwin S, Tecklin JS (1990) Cardiopulmonary Physical Therapy. 2nd edn. The CV Mosby Company, (1991) St Louis.

23 McArdle WD, Katch FI, Katch VL (1991) Evercise Physiology: Energy, Nutrition, and Human Performance. 3rd edn. Lea and Febiger, Philadelphia: Appendix D.

24 Glaser RM. Davis GM (1989) The wheelchair-dependent individual. In: Franklin BA, Gordon S, Timmis GC, editors. Exercise in Modern Medicine. Baltimore: Williams and Wilkins, Baltimore: 250.

25 Siegel S, Castellan NJ (1988) Nonparametric Statistics for the Behavioral Sciences. 2nd edn. McGraw-Hill, New York.

26 Landis JR, Koch GG (1977) The measurement of observer agreement for categorical data. Biometrics. 33: $159-174$. 